\title{
Is Full-Length Intramedullary Nail Necessary for Atypical Subtrochanteric Femoral Fracture Associated with Bisphosphonate?
}

\author{
Kwang-kyoun Kim', Seung kwon Ryu², Seok-Won Lee', Hyun-jae Cha' \\ 'Department of Orthopaedic Surgery, Konyang University Hospital, Daejeon; \\ ${ }^{2}$ Department of Orthopaedic Surgery, Yuseong Sun Hospital, Daejeon, Korea
}

\author{
Corresponding author \\ Kwang-kyoun Kim \\ Department of Orthopaedic Surgery, Konyang \\ University Hospital, 158 Gwanjeodong-ro, \\ Seo-gu, Daejeon 35365, Korea \\ Tel: +82-42-600-6902 \\ Fax: +82-42-545-2373 \\ E-mail:kimajouos@gmail.com
}

Received: March 28, 2020

Revised: April 7, 2020

Accepted: April 19, 2020
Copyright $@ 2020$ The Korean Society for Bone and Mineral Research

This is an Open Access article distributed under the terms of the Creative Commons Attribution Non-Commercial License (https://creativecommons.org/licenses/by-nc/4.0/) which permits unrestricted non-commercial use, distribution, and reproduction in any medium, provided the original work is properly cited.

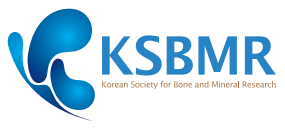

Background: American Society for Bone and Mineral Research recommend the use of intramedullary reconstruction of full length-nail for atypical subtrochanteric femoral fracture (ASFF). However, there is no study on the incidence of the ipsilateral femoral fracture after index operation of ASFF, and full-length nail has disadvantage as iatrogenic fracture and leg length discrepancy (LLD). The aim of this study was to investigate the incidence of ipsilateral secondary fracture after using partial-length nail, and to compare the outcomes on surgery of ASFF between partial length-nails and full length-nails. Methods: Forty-five consecutive fractures with ASFFs which had undergone intramedullary fixation using cephalomedullary nail between 2011 and 2018 were enrolled. The 45 cases were grouped based on nail length into the partial-length nail group $(n=26)$ and the full-length nail group $(n=19)$. Ipsilateral secondary fracture, time to union, intraoperative iatrogenic fracture, metal failure, LLD, operative duration, and post-operative 24-hr blood loss were investigated. Results: There was no ipsilateral secondary fracture after index operation. There were no statistically significant differences between the partial-length nail and full-length nail groups in the time to union, LLD, and post-operative 24 -hr blood loss ( $P=0.427,0.478$, and 0.228 , respectively). Operative duration showed statistically significant difference between 2 groups $(P=0.034)$. Metal failure were occurred in 1 (3\%) case of the partial-length nail group and $2(10 \%)$ cases of the full-length nail group. latrogenic fractures during nail insertion occurred in 2 (7\%) cases of the partial-length-nail group and 3 cases (15\%) of the full-length nail group. Conclusions: Although large scale studies are required, our study indicate that full-length nails are not usually required for the treatment of ASFF.

Key Words: Diphosphonates · Fracture fixation · Intramedullary · Osteoporosis · Subtrochanteric fractures

\section{INTRODUCTION}

Bisphosphonates (BPs) reduce the overall risk of fractures in patients with osteoporosis, with a long-lasting beneficial effect but, recent reports have suggested that prolonged BP use may be related to severe suppression of bone turnover and lack of targeted remodeling of micro-damage, which results in low-energy atypical femur fracture (AFF).[1-3]

Surgical treatment for AFFs is recommended in cases of complete fractures and 
incomplete fracture with prodromal symptoms and presence of the dreaded black line on a radiograph.[4] Fracture healing by intramedullary nailing (IMN) is less affected by osteoclast function, and some reports suggested better results by plate fixation.[1] In atypical subtrochanteric femur fractures (ASFF), full-length nails are recommended for preventing ipsilateral subsequential femoral fracture.[1,5] However, severe bowing of the femur can result in a mismatch between the curvature of the IMN and the alignment of the femur. Mismatches are a risk factor for iatrogenic fractures and leg length discrepancy (LLD).[6,7]

Despite the known disadvantages of full-length nails, there have been no reports comparing the results of ASFF treated with full-length nails and partial-length nails. The aim of this study was to investigate the incidence of ipsilateral secondary fractures after using partial-length nails, and to determine whether the length of the nails affects the outcomes in the treatment of ASFF.

\section{METHODS}

All procedures were approved by the Institutional Review Board of Konyang University Hospital (KYUH 201910-013). We reviewed the medical records of patients undergoing surgical treatment for geriatric femoral fractures at 2 institutions between 2011 and 2018 and identified 72 cases (64 patients) with ASFFs, that met the 2013 American Society for Bone and Mineral Research task force document definition of AFFs.[1] Out of 72 ASFFs, incomplete fractures (16 cases), patients who have not been treated with BP more than at least 12 months (2 cases), short-term follow-up without union evidence (7 cases), and history of prednisolone $30 \mathrm{mg} /$ day over 3 months (cumulative dose $\geq 5 \mathrm{~g}$ ) (2 cases) were excluded. The final cohort included 38 patients with 45 fractures (Fig. 1).

In this study, 43 number of female and 2 number of male enrolled, and the mean age was 76.5 years (range, 59-88). Bone mineral density (BMD) values were determined by dual energy X-ray absorptiometry scans (Lunar iDXA; GE Healthcare lunar, Madison, WI, USA) of the lumbar spine and proximal femur of the uninjured hip. In cases of prior surgery on opposite hip, only lumbar spine BMD was evaluated.

In the index surgery, the opposite femur showed radiologic abnormal findings in 21 cases (47\%) of enrolled 45 cases. 5 patients $(11 \%)$ had already previous fractures at opposite femur. There were 12 (27\%) cases of incomplete fractures with the dreaded black line, and 4 (9\%) cases of only cortical hypertrophy. Among 12 patients with opposite incomplete fracture with dreaded black line, preventive fixation was performed in 6 cases and conservative treatment in 6 cases. Conservative treatment was performed in all 4 cases with only cortical hypertrophy. Five out of 10 conservative treatments progressed to complete fracture. AFF occurred in one patients who did not stop BP among the 24 patients who had no abnormal finding in the opposite femur.

The 45 cases were grouped based on nail length into the partial-length nail group $(n=26)$ and the full-length nail group $(n=19)$. Partial length-nail group used proximal femoral anti-rotation nails (PFNA; Synthes, Oberdorf, Switzerland; $200 \mathrm{~mm}$ ) in 24 cases and INTERTAN (Smith \& Neph-

Atypical subtrochanteric fracture $(n=72)$

- Incomplete fracture $(n=16$

- No treated with BP more than at least 12 months $(n=2)$

- $<1$ year follow-up without union evidence $(n=7)$

- History of prednisolone $30 \mathrm{mg} /$ day over 3 months (cumulative dose $\geq 5 \mathrm{~g})(\mathrm{n}=2$ )

Partial length-nail used group $(n=26)$

Full length-nail used group $(n=19)$

Fig. 1. Flowchart and proportion of cases with nail length.

- 4 patients were deceased at telephone interview - 45 cases of telephone interview were available from patients or guardian 
ew, Memphis,. TN, USA; $180 \mathrm{~mm}$ ) in 2 cases. Full lengthnail group used long PFNA (340 mm, $380 \mathrm{~mm}$ ) in 13 cases and reconstruction trochanteric antegrade nail (Smith \& Nephew; 340 mm, $380 \mathrm{~mm}$ ) in 6 cases. The full-length nail was defined by the position of the nail's tip past 3 quarts of the femur. Radiological follow-up period was an average of 1.9 years (range, 1-5.7 years). The radiological outcomes were evaluated by the incidence of ipsilateral secondary fracture, time to union, neck-shaft angle (NSA), LLD, and metal failure. Radiographic union was defined as bridging across 3 or 4 cortices and/or loss of a visible fracture line based on standard anteroposterior (AP) and lateral femoral radiographs.[8] Delayed union of fracture was defined as radiographic lack of evidence of union up to 6 months after surgery. NSA was evaluated in an immediate post-operative AP radiograph of the hip on the injured side and the contralateral uninjured side. The difference between the 2 sides was then calculated. Good reduction was determined as having less than 5 degrees of angulation. NSA was measured in only 40 cases because the proximal femur on the other side had already undergone surgery in 5 cases at the time of index operation. The measurements were performed by 2 residents and the numbers were averaged. The Pearson's correlation co-efficient r-value obtained was 0.497 , denoting a moderate degree of correlation between the 2 observers.
LLD was measured in both femur excluding cases of previous deformity and operation affecting leg length on the contralateral side. Femur lengths were measured from the highest point on the femoral head to the lowest point of the medial femoral condyle on post-operative scanogram. [9] The measurements were performed by 2 residents and the numbers were averaged. The Pearson's correlation coefficient $r$-value obtained was 0.897 , denoting a strong degree of correlation between the 2 observers.

Telephone interviews were conducted to investigate the long-term incidence of ipsilateral secondary fractures. Four patients were deceased at the time of the telephone interview ( 2 patients in partial-length nail group, 2 cases in fulllength-nail group). Information of all enrolled 45 cases were obtained from patients or the patients legal guardians and the follow up duration was mean of 3.9 years (range, 2-7.2 years).

Medication history was evaluated by reviewing the patients' medical records. The mean duration of BP therapy before fracture was 3.9 years (range, 1-12 years) and all cases discontinued BPs at the time of surgery. However, 2 cases (5\%) had BPs administered again from the endocrinology department in the outpatient clinic. We were unable to obtain any information on the post-operative medication for osteoporosis from 2 (5\%) cases. BP was exchanged for teriparatide injection in 10 patients (22\%) and raloxi-

Table 1. Demographic data and postoperative outcomes between partial length-nail group and full length-nail group

\begin{tabular}{|c|c|c|c|}
\hline Variables & $P(n=26)$ & $F(n=19)$ & $P$-value \\
\hline Age (yr) & 72.1 (59 to 88) & 70.2 (60 to 85) & 0.341 \\
\hline Lumbar spine BMD (T-score) & $-2.2 \pm 0.6(-3.8$ to 1.4$)$ & $-2.3 \pm 0.9(-4,2$ to -1.3$)$ & 0.104 \\
\hline $\mathrm{BMI}\left(\mathrm{kg} / \mathrm{m}^{2}\right)$ & 20.3 (18.2 to 28.4$)$ & 21.9 (19.4 to 28.2) & 0.215 \\
\hline Bisphosphonate discontinuation & $24(92.3)$ & $17(89.5)$ & 1.000 \\
\hline Bisphosphonate continuation & $1(3.8)$ & $1(5.3)$ & 1.000 \\
\hline Ipsilateral secondary fracture & $0(0.0)$ & $0(0.0)$ & 1.000 \\
\hline Neck-shaft angle & $126.3(117.4$ to 136.1$)$ & 125.6 (113.0 to 134.5$)$ & 0.571 \\
\hline Good alignment $(n=40, P: F=23: 17)$ & $20(76.9)$ & $15(78.9)$ & 1.000 \\
\hline Fracture union & $25(96.2)$ & $17(89.5)$ & 0.565 \\
\hline Time to union (months) & $10.3 \pm 3.9(6$ to 15$)$ & $10.8 \pm 4.0(6$ to 15$)$ & 0.429 \\
\hline latrogenic fracture & $2(7.7)$ & $3(15.8)$ & 0.638 \\
\hline Metal failure & $1(3.8)$ & $2(10.5)$ & 0.565 \\
\hline Leg length discrepancy (mm) & $6.7 \pm 2.3$ (2 to 11$)$ & $5.6 \pm 3.3(1$ to 10$)$ & 0.478 \\
\hline Postoperative 24-hour blood loss (mL) & $128 \pm 80$ (35 to 310$)$ & $149 \pm 83(100$ to 300$)$ & 0.228 \\
\hline Operative duration (min) & $65.9 \pm 23.5$ (35 to 120$)$ & $97.6 \pm 25.3$ (55 to 155$)$ & 0.034 \\
\hline
\end{tabular}

The data is presented as mean \pm standard deviation (range) or number (\%).

$\mathrm{BMD}$, bone mineral density; BMI, body mass index; P, partial length-nails group; F, full length-nails group. 
fene in $5(11 \%)$ patients after index surgery.

In only one case, open reduction with cerclage wiring was conducted. Operative duration was evaluated by anesthesia records, and post-operative 24-hr blood loss were calculated by Gross.[10]

\section{Statistical analysis}

Statistical analysis was performed using the SPSS software (version 20.0; IBM Corp., Armonk, NY, USA). The $\chi^{2}$ test and Fisher's exact test were used to compare categorical variables and the Student's $t$-test and Mann-Whitney $U$ test were used to compare continuous variables. The level of significance was $P<0.05$.

\section{RESULTS}

There were no statistically significant differences between partial-length nail group and full-length nail group in terms of age, BMD, body mass index (in order, $P=0.341,0.104$, and 0.215 ). There was no ipsilateral subsequential femoral fracture after index operation on both group. Demographic data was shown in Table 1. There were no statistically significant differences between the partial-length nail and full-length nail groups in the time to union, NSA, good alignment, LLD, iatrogenic fracture, metal failure, and postoperative 24 -hr blood loss ( $P=0.429,0.571,1.000,0.478$, $0.683,0.565$, and 0.228 , respectively). The 3 cases of metal
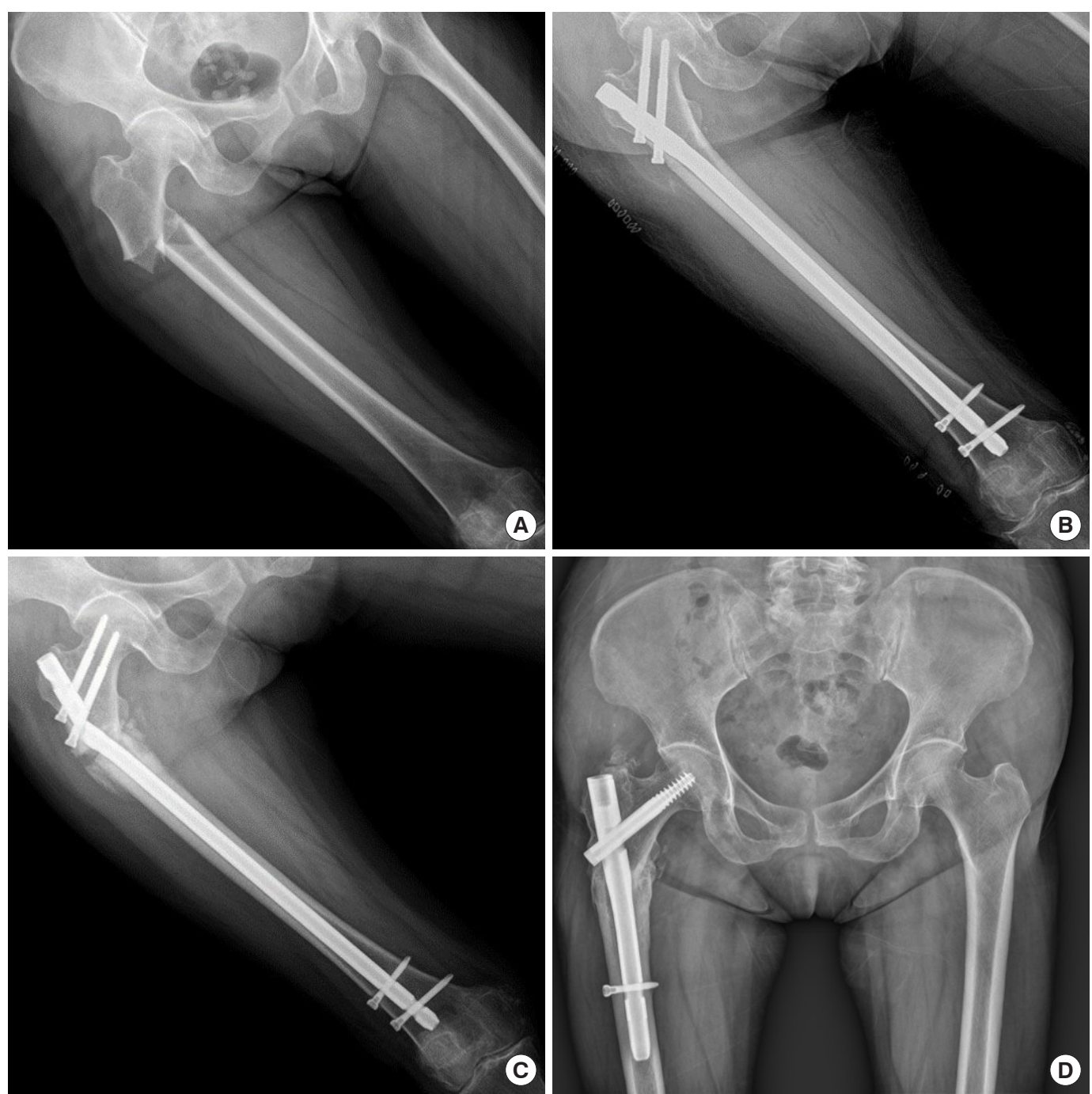

Fig. 2. A 75-year-old female with atypical subtrochanteric femur fracture (A) preoperative radiograph of $(B)$ immediate postoperative radiograph (C) 5 months postoperatively, nonunion and breakage of the nail at the insertion hole of the lag screw (D) six months later, complete healing was observed after revision with partial-length nail. 

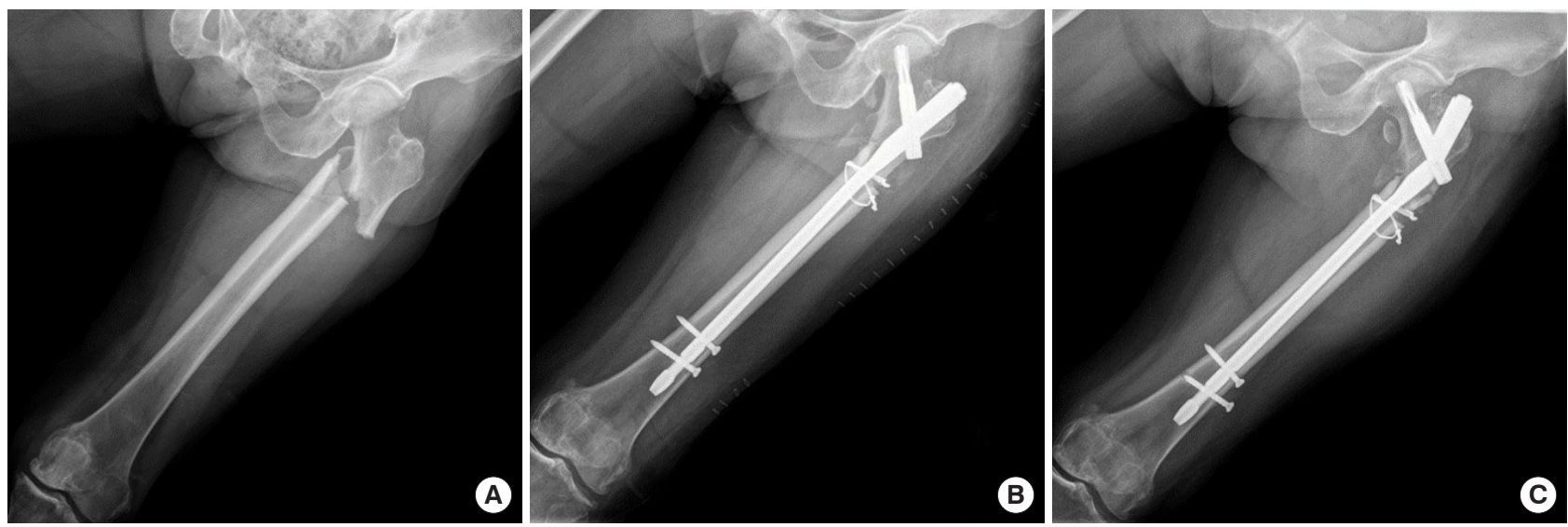

Fig. 3. An 85-year-old female with atypical subtrochanteric femur fracture (A) preoperative radiograph (B) immediate postoperative radiograph (C) 5 months postoperatively, nonunion and breakage of the nail at the insertion hole of the lag screw.
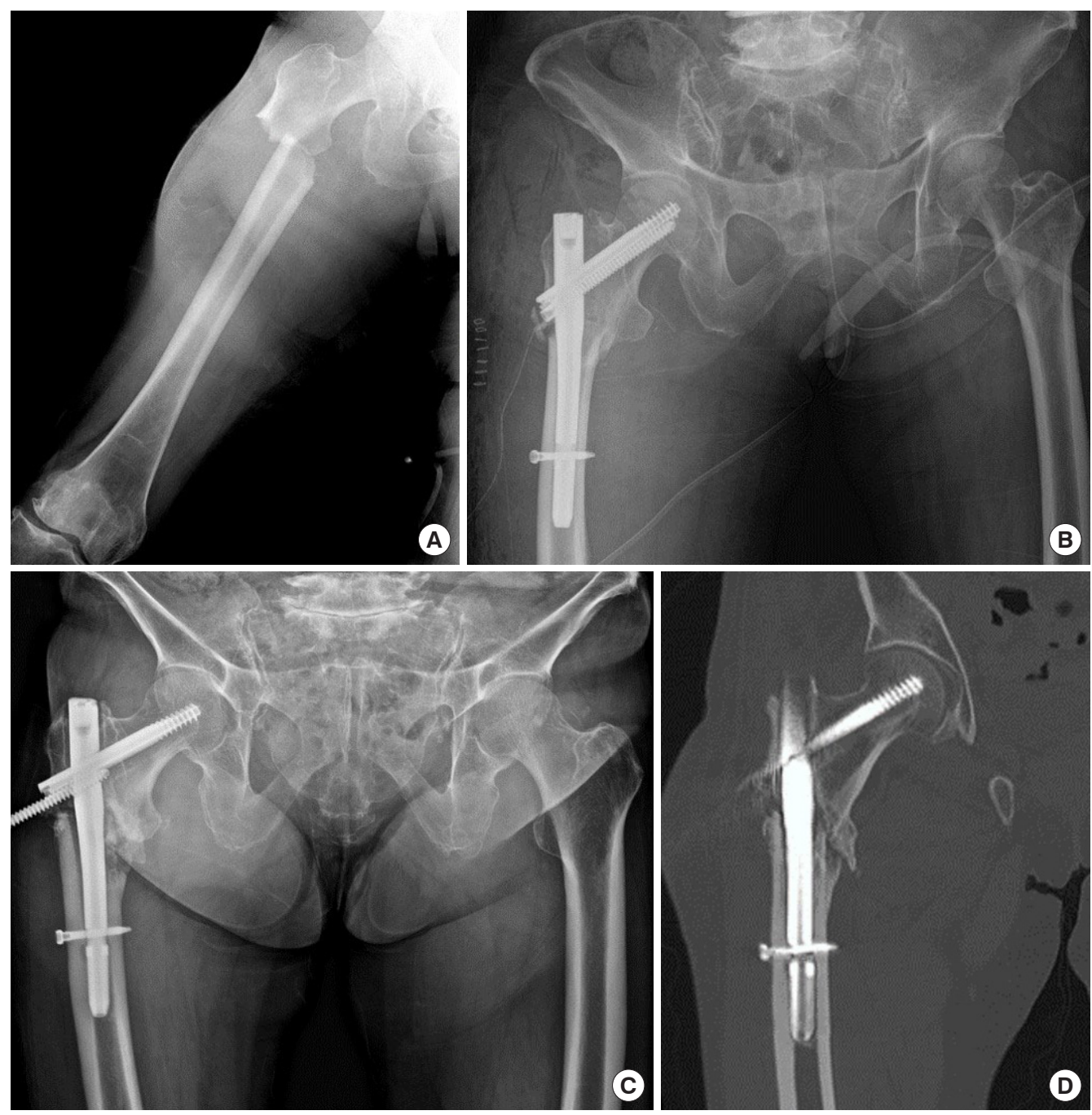

Fig. 4. An 80-year-old female with atypical subtrochanteric femur fracture (A) preoperative radiograph of (B) immediate postoperative radiograph (C) 12 months postoperatively, appearance of a lateral migration of the inferior lag screw and medial migration of the superior lag screw (D) computed tomography showed nonunion and breakage of the nail at the insertion hole of the lag screw. 

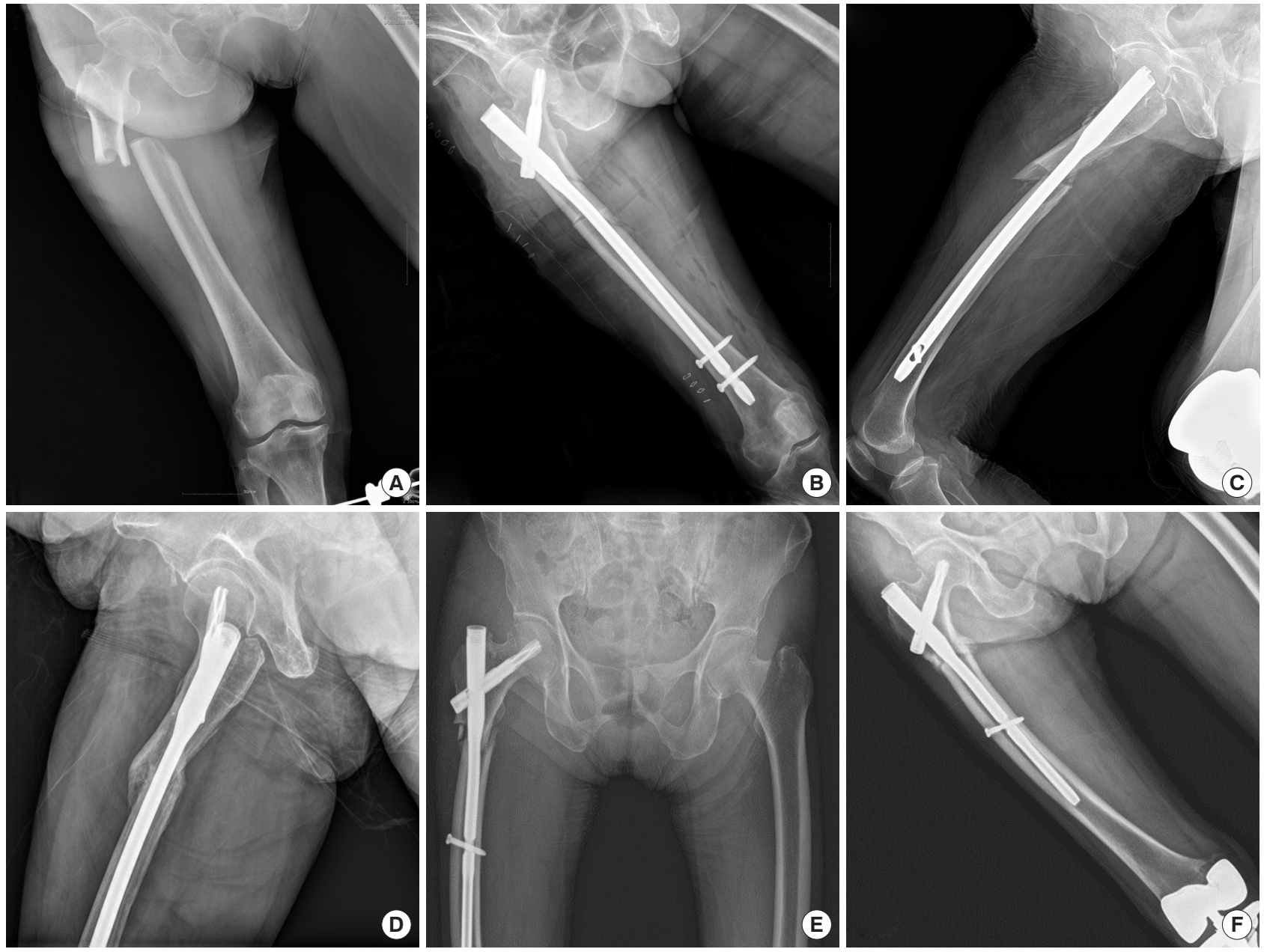

Fig. 5. (A) A 78-year-old female, radiograph shows atypical subtrochantric femoral fracture. (B) latrogenic fracture of medial femoral cortex was occurred during nail insertion. (C) On lateral view, the entry point of nail was positioned more anterior to the tip of greater trochanter and there was a large fracture gap and iatrogenic fracture of anterior cortex. (D) Six months later, complete healing was observed. (E) A 76-year-old female, iatrogenic comminuted fracture of proximal femur was occurred during nail insertion. (F) Ten months later, complete healing was observed.

failure were excluded from the statistical analyses of the time to union. Forty-two cases (95.7\%) achieved complete bone union without any further surgical intervention, although delayed union was observed in 25 cases (55\%). Metal failure occurred in 1 case of the partial-length nail group (3\%) and in 2 cases of the full-length nail group (10\%) and all 3 cases were revised and achieved union (Fig. 2-4). latrogenic fractures during nail insertion occurred in 2 cases (7\%) of the partial-length nail group and 3 cases $(15 \%)$ of the full-length nail group (Fig. 5). Operative duration showed statistically significant difference between partial-length nail group and full-length nail group ( $P=0.034)$. AFF occurred in 5 cases out of 10 conservative treatments for abnormal radiologic finding. BP persisted in 2 patients, of which contralateral ASFF occurred after post-operative 15 months in one patient and metal failure after post-operative 6 months in another patient.

\section{DISCUSSION}

This study is the first report to question the requirement for full length nails in the treatment of ASFF. There was no ipsilateral subsequential femoral fracture regardless of the nail length. In a literature review, there were a few case reports with ipsilateral secondary fracture at the location of proximal transverse interlocking locking screws after long IMN for AFF, and at the distal interlocking screw insertion site of long IMN with subtrochanteric fracture.[11-13] In- 
correctly drilled hole for the screw can serves as stress riser in the fracture. Therefore, special care must be taken when making interlocking screw. We were unable to find any reports on ipsilateral subsequential femoral fractures around or below of partial-length nail fixation after operation. Atypical femoral fractures are usually located in the subtrochanter and diaphysis. Koh et al. [14] found that atypical lesions were clustered at the region of maximal tensile loading and none were in regions subject to compressive loading. Kim et al. [15] demonstrated that the AFF location was moved from the subtrochanteric area to the diaphyseal area with greater lateral bowing angle. Therefore, it is assumed that the risk of ipsilateral subsequential fracture in the diaphysis will not increase if the stress applied to the lateral cortex of the femur does not increase substantially due to changes in load transfer or lower limb geometry after surgery with partial-length nail in the ASFF.

AFF is known to have a more delayed healing than a standard femur fracture which usually heals within 6 months. [16-18] Our results of time to union was a mean of $10.3 \pm$ 3.9 months (range, 4-15 months) in the partial length group and 10.8 \pm 4.0 months (range, 5-15 months) in the full-length nail group. Egol et al. [19] reported that the mean healing time for the anatomically reduced group was 7.1 months (range, 2-12 months) and the non-anatomically reduced fractures healed in 10.8 months (range, 2-18 months). Cho et al. [13] reported that mean time to union after cephalomedullary nailing of ASFF was 10.7 months. Miura et al. [20] reported that bone healing time was a mean of 10 months in AFF (range, 6-14.5 months). Considering our results and review of the literatures, we suggested waiting 10 months for the healing without hasty surgical intervention.

For inherently unstable ASFF, the use of a cephalomedullary nail is recommended to increase fracture stability. $[21,22]$ Authors have suggested that there should be a minimum distance of $5 \mathrm{~cm}$ between the distal locking hole and the fracture line in a subtrochanteric fracture.[23] In most ASFFs, the fracture line is a low transversal or short oblique pattern located just below the lesser trochanter so that partial-length nail can provide sufficient distance between the fracture and distal screw holes. Working length and distance from the fracture to the distal interlocking screw of partial-length nail are shorter than in the full-length nail, but the distal screws can be located in the diaphysis rather than the metaphyseal flare. As a nail is inserted at the distal femur closed to knee joint, the stress of the screw is inversely higher because a longer locking screw is required and unsupported span of the screw is increased.[24] In a case of non-union with metal failure in the post-operative 5 months after surgery, we achieved bone union with increased nail-cortical bone contact and more secure fixation of distal interlocking screw after changing to a larger diameter partial-length nail (Fig. 2).

There were 3 cases of metal failure in our study, all of which occurred at the lag screw aperture level, where the cross section of the nail is reduced considerably by up to 70\%.[25] Varus malreduction and inadequate proximal 3 points fixation (lateral cortex engagement, tip contact at the greater trochanteric cortex, tip apex distance $<25$ $\mathrm{mm}$ ) are shown to be associated with metal failure.[26] Incorrect drilling also can damage the lag screw aperture, which could further weaken the nail. Therefore, for inherently unstable ASFF, anatomical reduction of the fracture, 3 points fixation, and precise reaming technique are especially needed to avoid potential nonunion and metal failure at the level of the lag screw. Distal locking screw breakage or loosening is a precursor of the proximal metal failure with varus malreduction, so careful observation is necessary (Fig. 3C).

In our study, iatrogenic fractures during nail insertion occurred in 2 cases of the partial-length nail group and 3 cases of the full-length nail group. Severe anterior bowing of the femur can result in mismatch between the IMN and the alignment of the femur. Such mismatch is a risk factor for anterior cortical perforation of the distal femur with subtrochanteric fractures and LLD with fractures of the femoral shaft.[27,28] Park et al. [27] reported that IMN with the smallest radius of curvature and diameter provided the optimal fit without iatrogenic fracture in the bowed femur. In addition to the selection of nails, the entry point of the nail is also very important and should be at the tip of greater trochanter. Anterior transition of the point of entry may result in a burst fracture of the proximal femur during the IMN procedure (Fig. 5).

For the placement of distal interlocking screws, various innovative techniques have been described, such as radiolucent drill guides, image intensifier mounted targeting devices and laser guided systems.[29-31] Despite all of these techniques, the free hand technique remains popular for the placement of distal interlocking screw in the full- 
length nail.[32] Using the full-length nail resulted in a longer operative duration than for the partial-length nail in our study. There is an increased operative duration in the full-length nail using the free hand technique than partiallength nail using targeting device for the placement of distal interlocking screw in our study. Increased operative duration results in increased surgical site infection, as well as more chance in radiation exposure, leading to an increased risk of solid tumors and cataracts.[33-36] Schilcher et al. [37] demonstrated that following AFF, discontinuing BP therapy achieved a 70\% per-year reduction in the relative risk of developing contralateral atypical fracture. Dell et al. [38] showed the incidence of bilateral AFFs to be $41 \%$ in patients who continued BPs for 3 or more years after the index AFF, compared with $19 \%$ in patients who discontinued the drug. BP was discontinued in 43 (95\%) cases in our study, and this is presumed to have affected the absence of ipsilateral secondary fracture. Of the 24 (53\%) cases with no lesion on contralateral side at index surgery, AFF occurred in only one case which continued to use BP. So, BP should be discontinued following diagnosis with AFF.

The main limitation of the study is the small, unmatched sample sizes and retrospective nature of the study. Given the low incidence of ASFF quoted in the literature, a large multicenter study is required. Some of the clinical information was obtained by telephone interviews with the patient or guardian, which may have resulted limited information if not correctly remembered. In particular, the telephone interview could not reveal an incomplete fracture. Insufficient follow up periods and high mortality rate of hip fracture in old age also may have had an impact on the incidence of the ipsilateral femoral fracture.

However, Despite the many drawbacks mentioned above, the strengths of this study are that it is the first report to question the requirement for full-length nails in the treatment of ASFF.

Although large scale studies are required, our study indicate that full-length nails are not usually required for the treatment of ASFF and BP should be discontinued after diagnosis with ASFF in order to prevent secondary fracture.

\section{DECLARATIONS}

\section{Ethics approval and consent to participate}

This study was conducted according to the principles expressed in the Declaration of Helsinki and was approved by the Konyang University Hospital Research Ethics Committee (KYUH 2019-10-013).

\section{Conflict of interest}

No potential conflict of interest relevant to this article was reported.

\section{ORCID}

Kwang-kyoun Kim https://orcid.org/0000-0002-6844-5431

Seung kwon Ryu https://orcid.org/0000-0002-4492-995X

Seok-Won Lee https://orcid.org/0000-0002-0391-8103

\section{REFERENCES}

1. Shane E, Burr D, Ebeling PR, et al. Atypical subtrochanteric and diaphyseal femoral fractures: report of a task force of the American Society for Bone and Mineral Research. J Bone Miner Res 2010;25:2267-94.

2. Starr J, Tay YKD, Shane E. Current understanding of epidemiology, pathophysiology, and management of atypical femur fractures. Curr Osteoporos Rep 2018;16:519-29.

3. Neviaser AS, Lane JM, Lenart BA, et al. Low-energy femoral shaft fractures associated with alendronate use. J Orthop Trauma 2008;22:346-50.

4. Black DM, Abrahamsen B, Bouxsein ML, et al. Atypical femur fractures: review of epidemiology, relationship to bisphosphonates, prevention, and clinical management. Endocr Rev 2019;40:333-68.

5. Lee KJ, Min BW. Surgical treatment of the atypical femoral fracture: overcoming femoral bowing. Hip Pelvis 2018;30: 202-9.

6. Egol KA, Chang EY, Cvitkovic J, et al. Mismatch of current intramedullary nails with the anterior bow of the femur. $J$ Orthop Trauma 2004;18:410-5.

7. Park YC, Song HK, Zheng XL, et al. Intramedullary nailing for atypical femoral fracture with excessive anterolateral bowing. J Bone Joint Surg Am 2017;99:726-35.

8. Whelan DB, Bhandari M, McKee MD, et al. Interobserver and intraobserver variation in the assessment of the healing of tibial fractures after intramedullary fixation. J Bone Joint Surg Br 2002;84:15-8.

9. Vaidya R, Anderson B, Elbanna A, et al. CT scanogram for limb length discrepancy in comminuted femoral shaft fractures following IM nailing. Injury 2012;43:1176-81. 
10. Gross JB. Estimating allowable blood loss: corrected for dilution. Anesthesiology 1983;58:277-80.

11. Park KT, Lee KB. Sequential subtrochanteric femoral fracture after atypical diaphyseal fracture in a long-term bisphosphonate user: a case report. Acta Chir Orthop Traumatol Cech 2015;82:157-60.

12. Kim YS, Chung PH, Kang S, et al. A rare case of bilateral proximal femoral insufficiency fractures after interlocking IM nailing for bilateral atypical femoral shaft fractures. Arch Orthop Trauma Surg 2015;135:1227-32.

13. Cho JW, Oh CW, Leung F, et al. Healing of atypical subtrochanteric femur fractures after cephalomedullary nailing: which factors predict union? J Orthop Trauma 2017;31: 138-45.

14. Koh JS, Goh SK, Png MA, et al. Distribution of atypical fractures and cortical stress lesions in the femur: implications on pathophysiology. Singapore Med J 2011;52:77-80.

15. Kim JW, Kim JJ, Byun YS, et al. Factors affecting fracture location in atypical femoral fractures: a cross-sectional study with 147 patients. Injury 2017;48:1570-4.

16. Matre K, Havelin LI, Gjertsen JE, et al. Sliding hip screw versus IM nail in reverse oblique trochanteric and subtrochanteric fractures. A study of 2716 patients in the Norwegian Hip Fracture Register. Injury 2013;44:735-42.

17. Sanders R, Regazzoni P. Treatment of subtrochanteric femur fractures using the dynamic condylar screw. J Orthop Trauma 1989;3:206-13.

18. Yue B, Ng A, Tang H, et al. Delayed healing of lower limb fractures with bisphosphonate therapy. Ann R Coll Surg Engl 2015;97:333-8.

19. Egol KA, Park JH, Rosenberg ZS, et al. Healing delayed but generally reliable after bisphosphonate-associated complete femur fractures treated with IM nails. Clin Orthop Relat Res 2014;472:2728-34.

20. Miura T, Kijima H, Ishikawa N, et al. Comparison of atypical and osteoporotic femoral shaft fractures in the elderly: a multicenter study. Adv Orthop 2018;2018:1068053.

21. Forward DP, Doro CJ, O'Toole RV, et al. A biomechanical comparison of a locking plate, a nail, and a $95^{\circ}$ angled blade plate for fixation of subtrochanteric femoral fractures. J Orthop Trauma 2012;26:334-40.

22. Ozkan K, Türkmen İ, Sahin A, et al. A biomechanical comparison of proximal femoral nails and locking proximal anatomic femoral plates in femoral fracture fixation: a study on synthetic bones. Indian J Orthop 2015;49:347-
51.

23. Ongkiehong BF, Leemans R. Proximal femoral nail failure in a subtrochanteric fracture: the importance of fracture to distal locking screw distance. Inj Extra 2007;38:445-50.

24. Lin J, Lin SJ, Chen PQ, et al. Stress analysis of the distal locking screws for femoral interlocking nailing. J Orthop Res 2001;19:57-63.

25. von Rüden $C$, Hungerer $S$, Augat $P$, et al. Breakage of cephalomedullary nailing in operative treatment of trochanteric and subtrochanteric femoral fractures. Arch Orthop Trauma Surg 2015;135:179-85.

26. Abram SG, Pollard TC, Andrade AJ. Inadequate'three-point' proximal fixation predicts failure of the Gamma nail. Bone Joint J 2013;95B:825-30.

27. Park JH, Lee $Y$, Shon OJ, et al. Surgical tips of intramedullary nailing in severely bowed femurs in atypical femur fractures: simulation with 3D printed model. Injury 2016; 47:1318-24.

28. Oh HC, Park SJ, Yoon HK. Surgical treatment in atypical diaphyseal femoral fracture with anterior and lateral bowing. J Korean Orthop Assoc 2014;49:485-9.

29. Boraiah S, Barker JU, Lorich D. Efficacy of an aiming device for the placement of distal interlocking screws in trochanteric fixation nailing. Arch Orthop Trauma Surg 2009;129: 1177-82.

30. Barrick EF. Distal locking screw insertion using a cannulated drill bit: technical note. J Orthop Trauma 1993;7:248-51.

31. Steriopoulos KA, Kontakis GM, Katonis PG, et al. Placement of the distal locking screws of the femoral intramedullary nail without radiation. Arch Orthop Trauma Surg 1996;115: 43-4.

32. Hashemi-Nejad A, Garlick N, Goddard NJ. A simple jig to ease the insertion of distal screws in intramedullary locking nails. Injury 1994;25:407-8.

33. Cheng $H$, Chen BP, Soleas IM, et al. Prolonged operative duration increases risk of surgical site infections: a systematic review. Surg Infect (Larchmt) 2017;18:722-35.

34. Blattert TR, Fill UA, Kunz E, et al. Skill dependence of radiation exposure for the orthopaedic surgeon during interlocking nailing of long-bone shaft fractures: a clinical study. Arch Orthop Trauma Surg 2004;124:659-64.

35. Cheriachan D, Hughes AM, du Moulin WS, et al. lonizing radiation doses detected at the eye level of the primary surgeon during orthopaedic procedures. J Orthop Trauma 2016;30:e230-5. 
36. Hayda RA, Hsu RY, DePasse JM, et al. Radiation exposure and health risks for orthopaedic surgeons. J Am Acad Orthop Surg 2018;26:268-77.

37. Schilcher J, Michaëlsson K, Aspenberg P. Bisphosphonate use and atypical fractures of the femoral shaft. $N$ Engl $J$
Med 2011;364:1728-37.

38. Dell RM, Adams AL, Greene DF, et al. Incidence of atypical nontraumatic diaphyseal fractures of the femur. J Bone Miner Res 2012;27:2544-50. 